likely to fall. More seriously, medical schools are already short of bright working-class entrants $(2.5 \%$ have parents in social classes IV or V, which constitute about $30 \%$ of the population ${ }^{1}$ ), and this financial squeeze can only act as a further disincentive.

Good arguments can be produced for rethinking the whole system of student grants, ${ }^{2}$ but until that comes about the Government should think again about cutting them. We would urge it also to recognise that in equity clinical medical students should receive the same rate for their extra weeks as all students receive for the basic terms.

1 Royal Commission on Medical Education. Report. London: HMSO, 1968. (Cmnd 3569.)

${ }^{2}$ Anonymous. What universities should aim at. Nature $1982 ; 295$ :541.

\section{Mitral valve prolapse and a Marfanoid habitus}

Prolapse of the mitral valve may result from a variety of abnormalities of the valvular mechanism and the myocardium. The defect is common, affecting around one person in 20 of the general population, ${ }^{1-3}$ and it may produce no symptoms at all or those of disturbed cardiac function.

The course and prognosis in any affected individual seem likely to be directly related to the underlying disorder, so that to facilitate prognosis and management specific syndromes need to be sought within the large heterogeneous group of disorders where mitral valve prolapse is known to occur.

One common factor linking some categories of patients is an underlying connective tissue disease: mitral valve prolapse is a frequent complication of the Marfan syndrome ${ }^{4}$ and is occasionally encountered in osteogenesis imperfecta ${ }^{5}$ and the Ehlers-Danlos syndrome. ${ }^{6}$ Equally, people with mitral valve prolapse sometimes have additional non-specific musculoskeletal stigmata such as articular hypermobility (R Grahame, personal communication 1982), altered bodily proportions, ${ }^{7}$ and thoracic asymmetry. ${ }^{8}$ These anomalies may show that the cardiac abnormality in these patients is one facet of an illdefined generalised disorder of connective tissue.

This association is well known to dysmorphologists and clinical geneticists, but the lack of specificity of the extracardiac manifestations usually foils any attempt to delineate a syndrome. In a recent article in the American fournal of Medicine, however, Schutte and his colleagues in Texas have reported that they had identified a dominantly inherited syndrome of mitral valve prolapse in people with distinctive anthropometric characteristics. ${ }^{9}$ Their patients had narrow anteroposterior chest diameters and longer armspans than controls. Unfortunately, the altered habitus was present only in women, and the value of measuring bodily proportions as a diagnostic discriminant in sporadic patients with mitral valve prolapse is therefore limited.

From the genetic standpoint, Schutte et $a l^{9}$ claimed that their findings in first degree relatives in three families were indicative of autosomal dominant inheritance of the syndrome. The lack of pedigree data for formal analysis, however, and the fact that the habitus was not present in men make it difficult to accept their proposals unreservedly. Moreover, in two further instances the results of family studies were negative. Notwithstanding these reservations, however, the diagnostic appraisal of possible heart abnormalities of potentially affected close relatives of individuals with the syndrome seems to be warranted.
The question inevitably arises whether these patients have the Marfan syndrome. The full-blown syndrome, with disproportion of the length of the limbs, arachnodactyly, and dislocated ocular lenses is unmistakable. Nevertheless, atypical or partial examples abound, and as there are no absolute diagnostic criteria diagnostic certainty is often impossible. Schutte $e t a l^{9}$ were at pains, however, to exclude individuals with the stigmata of the Marfan syndrome from their series, so this red herring can probably be discounted.

In view of the complexity of the collagen molecule, and on the basis of precedents for extreme degrees of heterogeneity in other conditions, there seem likely to be numerous undelineated disorders of connective tissue where mitral valve prolapse is a syndromic component. Indeed, Schutte et $a l^{9}$ may have already recognised one such entity. These disorders are, however, "soft syndromes," and in the absence of any biochemical marker firm delineation is well-nigh impossible.

As with many problems in medical genetics, resolution of this diagnostic dilemma may ultimately be achieved through recombinant DNA technology.

Peter Beighton

Professor of Human Genetics,

University of Cape Town Medical School,

Observatory 7925 ,

South Africa

1 Procacci PM, Savran SV, Schreiter SL, Bryson AL. Prevalence of clinical mitral-valve prolapse in 1169 young women. $N$ Engl $\mathcal{f}$ Med 1976;294:1086-8.

${ }^{2}$ Markiewicz W, Stoner J, London E, Hunt SA, Popp RL. Mitral valve prolapse in one hundred presumably healthy young females. Circulation $1976 ; 53: 464-73$

${ }^{3}$ Davies MJ, Moore BP, Braimbridge MV. The floppy mitral valve. Study of incidence, pathology, and complications in surgical, necropsy, and forensic material. Br Heart $\mathcal{F} 1978 ; 40: 468-81$.

${ }^{4}$ Brown OR, DeMots H, Kloster FE, Roberts A, Menashe VD, Beals RK. Aortic root dilatation and mitral valve prolapse in Marfan's syndrome: an echocardiographic study. Circulation 1975;52:651-7.

${ }^{5}$ Wood SJ, Thomas J, Braimbridge MV. Mitral valve disease and open heart surgery in osteogenesis imperfecta tarda. Br Heart $\mathcal{f} 1973 ; 35: 103-6$.

${ }^{6}$ Brandt KD, Sumner RD, Ryan TJ, Cohen AS. Herniation of mitral leaflets in the Ehlers-Danlos syndrome. Am $₹$ Cardiol 1975;36:524-8.

'Salomon J, Shah P, Heinle RA. Thoracic skeletal abnormalities in idiopathic mitral valve prolapse. Am $\mathcal{F}$ Cardiol 1975;36:31-6.

${ }^{8}$ Udoshi MB, Shah A, Fisher VJ, Dolgin M. Incidence of mitral valve prolapse in subjects with thoracic skeletal abnormalities-a prospective study. Am Heart f 1979;97:303-11.

9 Schutte JE, Gaffney FA, Blend L, Blomqvist CG. Distinctive anthropometric characteristics of women with mitral valve prolapse. $\mathrm{Am} \mathcal{F} \mathrm{Med}$ $1981 ; 71: 533-8$.

\section{Immunotherapy reassessed}

For 20 years now research workers have been looking into the immunotherapy of cancer but clinicians still do not know whether it is useful for their patients.

The concept of a simple treatment that might "mop up" the last remaining cancer cell after initial treatment with surgery or radiotherapy is attractive. Medawar's work in the 1950s on tissue recognition and the rejection of foreign cells and proteins started a hunt for tumour-specific antigens. ${ }^{1}$ A series of experiments ${ }^{2-4}$ in specially inbred strains of mice showed that tumour-specific transplantation antigens did indeed exist in tumours induced in these mice by chemicals. The combination of this evidence with studies showing that immunotherapy (usually with $\mathrm{BCG}^{56}$ ) worked in experimental tumours in animals raised great hopes for the immunotherapy of human cancer. Sadly, these hopes were largely disappointed as overenthusiastic clinicians began to use "immunotherapy" in a 
chaotic fashion destined to give results that could not be assessed. Indeed, even while these studies were starting warning voices were suggesting that data from research on animals could not be used to develop a treatment for human tumours.

Naturally occurring cancers differ from the experimental models in several ways. They are weakly antigenic and are less susceptible to immunological attack. In addition, experimental immunotherapy in animals works only when small numbers of tumour cells $\left(<10 \times 10^{6}\right)$ are injected. As Old and Boyse ${ }^{7}$ wrote: "Despite the evident antigenicity of a variety of [tumours in] experimental animals, it is a fact that no immunological measure is known that will cause the rejection of an established malignant tumour." Experimental tumours, in contrast to most human cancers, grow rapidly with short doubling times and are biologically different from spontaneous tumours. The evidence also suggests that host resistance is more complex than was at first thought. ${ }^{8-11}$ These difficulties led Alexander ${ }^{12}$ to point out that we need more realistic models before we can hope to get the best out of clinical immunotherapy.

Given the shaky foundations of the subject, what have we achieved in two decades of endeavour? Clinical immunotherapy may be divided into various types-specific active, non-specific active, and passive immunotherapy. Most clinical studies have used a non-specific approach, usually administering BCG. Though many early non-randomised studies gave favourable results, most recent controlled trials have failed to show any benefit from immunotherapy. Some positive features have emerged, however. Firstly, injections of BCG or Corynebacterium parvum into the tumour or local application of dinitrochlorobenzene causes regression of nodules of malignant melanoma or breast cancer but without any useful systemic effect. Secondly, one randomised study ${ }^{13}$ of intrapleural BCG given as adjuvant treatment showed an improvement in the survival of patients with stage 1 lung cancer who had undergone complete removal of their primary tumour. This study is always quoted in support of immunotherapy-but the benefit of the treatment in routine use has not been established. Thirdly, some early studies of adjuvant BCG suggested that it improved survival in patients after resection of malignant melanoma that had spread to regional lymph nodes. These findings have not been supported in recent trials. Other trials with positive results have been either non-randomised or too preliminary and unsubstantiated, or have been contradicted by other trials.

Adjuvant immunotherapy is fraught with difficulties: the mechanisms of host resistance are not understood, microscopic tumour deposits cannot be monitored, and the correct dosage and timing of immunotherapeutic agents is unknown. Many new clinical tools are now available, ${ }^{14}$ including exciting developments such as idiotypic antibodies and antibodies conjugated to drugs and toxins. We must not repeat the mistakes of the past 20 years. The first step must be to improve our understanding of the detailed mechanisms of various types of immunotherapy. Secondly, careful trials are essential: only then will we know whether immunotherapy is a sound treatment of cancer. Barber" ${ }^{15}$ has written that "the principal disadvantage of immunotherapy is that it does not work very well, and often does not work at all." He might have said that we do not know whether it works because we have yet to test the hypothesis.

C J Williams

Senior Lecturer and Honorary Consultant,

CRC Medical Oncology Unit,

Southampton General Hospital, Southampton SO9 4XY
${ }^{1}$ Medawar PB, ed. The immunology of transplantation. In: The Harvey lectures. New York: Academic Press, 1956-7: 144-76.

${ }^{2}$ Foley EJ. Antigenic properties of methylcholanthrene-induced tumors in mice of strain of origin. Cancer Res 1953;13:835-7.

${ }^{3}$ Prehn RT, Main JM. Immunity to methylcholanthrene-induced sarcomas. FNCI 1957;18:769-78.

${ }^{4}$ Klein G, Sjogren HO, Klein E, Hellstrom KE. Demonstration of resistance against methylcholanthrene-induced sarcomas in the primary autochthonous host. Cancer Res 1960;20:1561-72.

${ }^{5}$ Mitchell MS. Studies on the immunological effects of BCG and its components: theoretical and therapeutic implications. Biomedicine 1976; $24: 209-13$

${ }^{6}$ White RG. The adjuvant effect of microbial products on the immune response. Annu Rev Microbiol 1976;30:579-600.

${ }^{7}$ Old LJ, Boyse EA. Specific antigens of tumors and leukemias of experimental animals. Med Clin North Am 1966;50:901-12.

${ }^{8}$ Hibbs JB Jr, Lambert LH Jr, Remington JS. Possible role of macrophage mediated nonspecific cytotoxicity in tumour resistance. Nature 1972; $235: 48-50$.

' Perlmann P, Perlmann H, Wigzell H. Lymphocyte mediated cytotoxicity in vitro: induction and inhibition by humoral antibodies and nature of effector cells. Transplantation Reviews 1972;13:91-116.

${ }^{10}$ Bast RC Jr, Zbar B, Borsos T, Rapp HJ. BCG and cancer. $N$ Engl $\mathcal{f}$ Med $1974 ; 290: 1413-20$.

${ }^{11}$ Bast RC Jr, Zbar B, Borsos T, Rapp HJ. BCG and cancer. N Engl f Med $1974 ; 290: 1458-69$.

12 Alexander P. Back to the drawing board-the need for more realistic model systems for immunotherapy. Cancer 1977;40:467-70.

${ }^{13}$ McKneally KF, Marer CM, Kausel HW. Regional immunotherapy of lung cancer using postoperative intrapleural BCG. In: Terry WD, Windhorst D, eds. Immunotherapy of cancer: present status of trials in man. New York: Raven Press, 1978.

14 Goodnight JE, Morton DL. Immunotherapy of cancer: current status. Prog Exp Tumor Res 1980;25:61-88.

${ }^{15}$ Barber HR. Immunology in tumor therapeutics: an overview. Del Med $\mathcal{f}$ $1980 ; 52: 197-209$.

\section{Preventive medicine in general practice}

General practitioners and other health professionals providing primary care must take the main share of preventive medicine in the next decade. Co-operation with community physicians will become increasingly important as they evolve roles which expand far beyond those of the pre-1974 medical officers of health (though the contribution by medical officers of health to prevention of disease by technical means was remarkably successful). Nowadays, however, health education and promotion have become important growing areas in preventive medicine, posing different problems from those of the past but ones in urgent need of solution.

How is the general practitioner to meet these challenges? Many already accept their obligation in prevention and recognise the unique opportunities that general practice provides. But they and their less persuadable colleagues may protest, with justification, that they are so occupied in the business of triage, diagnosis, and treatment and support of the chronically sick that they are unable to devote more than a small fraction of their time to prevention. The preventive efforts they do make are likely to be confined to traditional measures, such as simple screening procedures and immunisations. The report by the Royal College of General Practitioners ${ }^{1}$ is right to assert that "The promotion of health is the part of preventive work furthest from most doctors' habits of thought and action. It entails helping people to learn and to accept responsibility for their own well-being."

The first hurdle to be cleared is, indeed, a psychological one. Doctors have to recognise that their independence and intellectual prowess may need to be tempered by the ability to function in a team, to learn the skills of communication, and, perhaps most important, to assume an equal status with members of the public as well as other health professionals. 